\title{
Téoros
}

Revue de recherche en tourisme

\section{Le tourisme en milieu autochtone, c'est...}

Points de vue autochtones sur l'industrie

\section{Michel Noël et Marie-Claude Cleary}

Volume 17, numéro 2, été 1998

L'industrie touristique autochtone

URI : https://id.erudit.org/iderudit/1072277ar

DOI : https://doi.org/10.7202/1072277ar

Aller au sommaire du numéro

Éditeur(s)

Université du Québec à Montréal

ISSN

0712-8657 (imprimé)

1923-2705 (numérique)

Découvrir la revue

Citer ce document

Noël, M. \& Cleary, M.-C. (1998). Le tourisme en milieu autochtone, c'est... Points de vue autochtones sur l'industrie. Téoros, 17(2), 42-43.

https://doi.org/10.7202/1072277ar d'utilisation que vous pouvez consulter en ligne.

https://apropos.erudit.org/fr/usagers/politique-dutilisation/ 


\section{fring..... \\ LE TOURISME EN MILIEU AUTOCHTONE, C'EST...}

POINTS DE VUE AUTOCHTONES SUR L'INDUSTRIE

\section{Propos recueillis par Michel Noël avec la collaboration de Marie-Claude Cleary}

Ils sont de plus en plus nombreux les autochtones qui prennent en main le développement touristique de leur territoire. Cette prise en charge, dont plusieurs cas témoignent, $n$ 'est cependant pas sans mettre au jour certains problèmes particuliers, dont les interrogations souleves par la mise en tourisme de leur culture, les besoins économiques, les contraintes liées à l'exploitation touristiqué. Les témoignages qui suivent révelent quelques préoccupations des autochtones quant au développement de a leur industrie.

\section{AURÉLIEN GILL}

Le tourisme chez les autochtones est une sorte de grande organisation familiale où les activités traditionnelles se convertissent en activités contemporaines. C'est aussi accueillir les non autochtones en quête de ressourcement dans un environnement de découverte afin de vivre un échange interculturel. Le tourisme chez les autochtones permet un rapprochement de deux cultures ainsi qu'une valorisation des autochtones et de leur milieu.

Le tourisme chez les autochtones est un élément important et même essentiel de l'offre touristique canadienne, C'est aussi une industrie qui produit de l'argent nouveau réparti dans la vie socio-économique et culturelle des communautés.

Le tourisme chez les autochtones va s'implanter sur une base définitive dans le réseau et permettra aux autochtones de se structurer et de se développer.

\section{DOMINIQUE RANKIN}

Aujourd'hui, le tourisme chez les autochtones prend une place très importante. On est contents de recevoir les touristes et de rentrer en contact avec eux pour leur faire connaitre notre culture, notre peuple ainsi que notre spiritualité. Les Européens et aussi les Québécois maintenant, viennent découvrir une nouvelle culture et une nouvelle nature. On les sensibilise à nos modes de vie d'autrefois et à nos modes de vie actuels.

Il s'agit d'une industrie assez grande qui crée de l'emploi chez les jeunes des communautés autochtones. Ces emplois permettent aux jeunes d'acquérir des connaissances et de l'experience tout en les rapprochant de leur culture. Cependant, il faut s'assurer que l'industrie ne devienne pas trop grande si l'on veut préserver ce qui appartient à nos peuples.

Dans un futur proche il devrait y avoir beaucoup d'argent investi dans le tourisme. Il faut faire attention à cette a grosse machine w, être prudent, car ça peut être dangereux pour les autochtones.

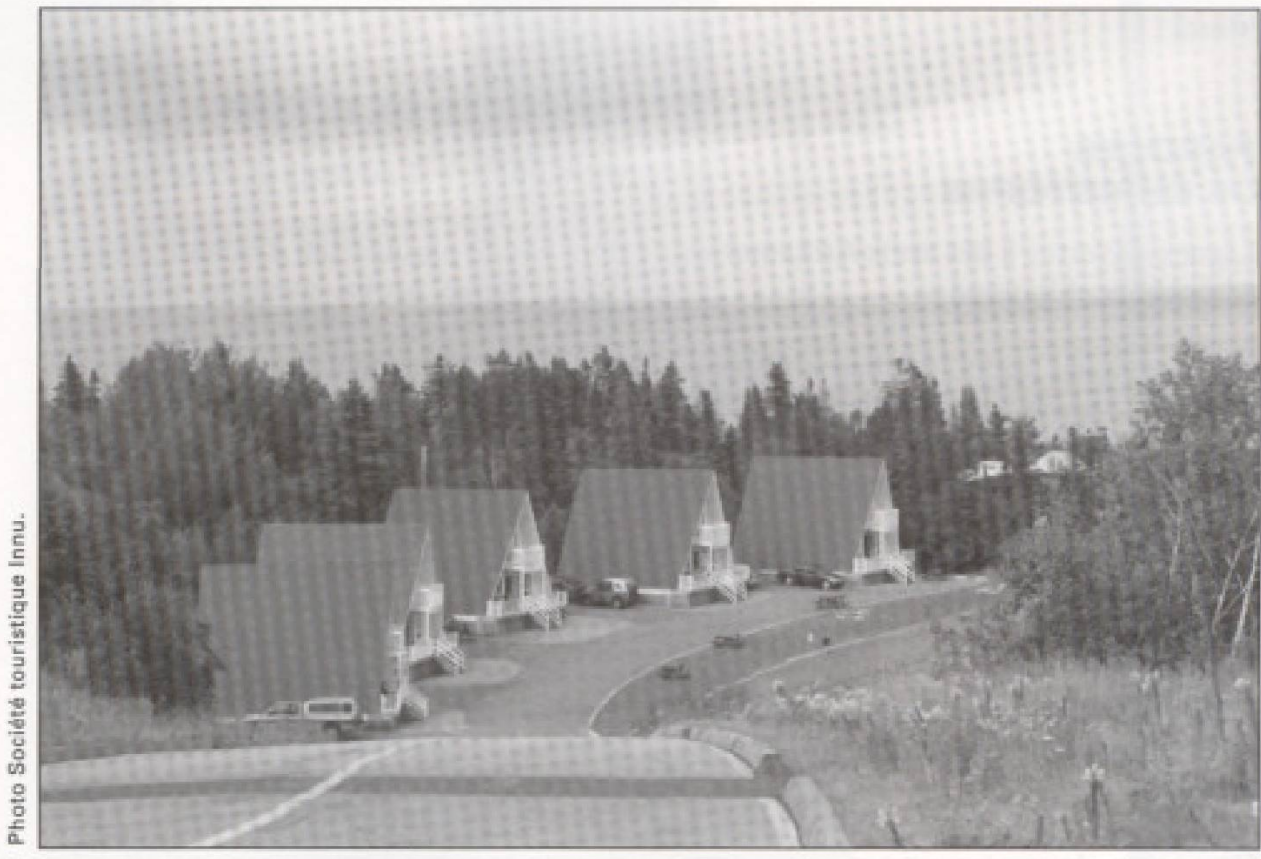

Infrastructures touristiques modernes aux Escoumins (Essipit). 


\section{HARRY ST-DENIS}

Aboriginal tourism today is something extremely important but unfortunately under-developed.

If it is developed correctly, it is more important than any other industry, like forestry or mining. If it is managed correctly, it can be longer-lasting and can create excellent and more meaningful jobs for native people.

Right now, there is a lack of financial assistance. If we want to develop aboriginal tourism we will need more help from the federal and the provincial.

\section{RÉGINALD VOLLANT}

Le tourisme chez les autochtones en région, la Côte Nord par exemple, est présentement en développement, il commence. Les gens ont identifié le tourisme comme étant un excellent moyen de croissance, c'est pourquoi on travaille à mettre sur pied des projets d'attraits touristiques.

Il s'agit d'une industrie très importante surtout si l'on considère que c'est un des principaux véhicules pour se faire connaître, se donner de la visibilité ainsi que pour faire passer des messages.

Ici, dans notre communauté, on vient tout juste de terminer un magnifique projet de musée. Les développements futurs doivent surtout se concentrer à ce genre de projets. Il faut accentuer les éléments culturels et ethnoculturels. Les attraits touristiques présentés doivent être authentiques et actuels car les gens ne cherchent plus ce qui est * folklorique *.

\section{CLIFFORD MOAR}

Le tourisme chez les autochtones est actuellement en plein développement. C'est une alternative intéressante qui peut soutenir les pertes encourues par nos peuples dans le passé. Ça permet également l'utilisation et l'occupation du territoire traditionnel de façon continue.

C'est une industrie des plus importantes étant donné qu"elle peut être compatible avec la culture si elle est développée de façon ethnoculturelle. Elle permettra ainsi un développement non seulement économique, mais aussi culturel et même social.
Les données existantes montrent qu'il y aurait une place importante pour les initiatives de développement du tourisme chez les autochtones. De plus, ces derniers possèdent un grand territoire qui permettrait à une multitude de gens d'ceuvrer dans ce domaine. Il y a de la place pour tout le monde et pour une grande diversité de produits.

\section{VICTORIA GORDON}

The most prominent tourism products sold in Nunavik today are hunting and fishing. This type of tourism has been in the region for about twenty years. As for adventure tourism there are very little products that Nunavik do sell but its development is well on its way to be organized.

The industry of tourism has an impact on Nunavik with employment opportunities to the local people. There is a good potential for employment, whether it is an administrative or a service job. I also believe that not only will it bring a new economy to Nunavik, but that it will also give recognition to its people and their culture. Tourism is the chance to let others learn about the Inuit culture.

The Inuit are becoming more aware of the people's growing interest for their culture and land. With this awareness they took action to meet the demand on their own. With more people becoming interested in the benefits of being involved in tourism, the economy in the Inuit communities will grow.

\section{ANDREW DELISLE}

Le tourisme est une activité très importante pour les autochtones. Il faut faire de la promotion afin d'avoir la chance d'expliquer aux gens l'essence de notre culture. Il y a un intérêt évident, du monde en général, à découvrir la spiritualité de notre peuple. C'est le cercle de la vie qui ramène les gens vers des valeurs authentiques.

Nous avons donc le devoir de développer quelque chose de sérieux au point de vue touristique. Non seulement parce qu'il y a de bonnes possibilités pour le développement économique, mais aussi parce que de telles entreprises amènent une fierté pour notre peuple. (Rendez-vous autochtone 1997)

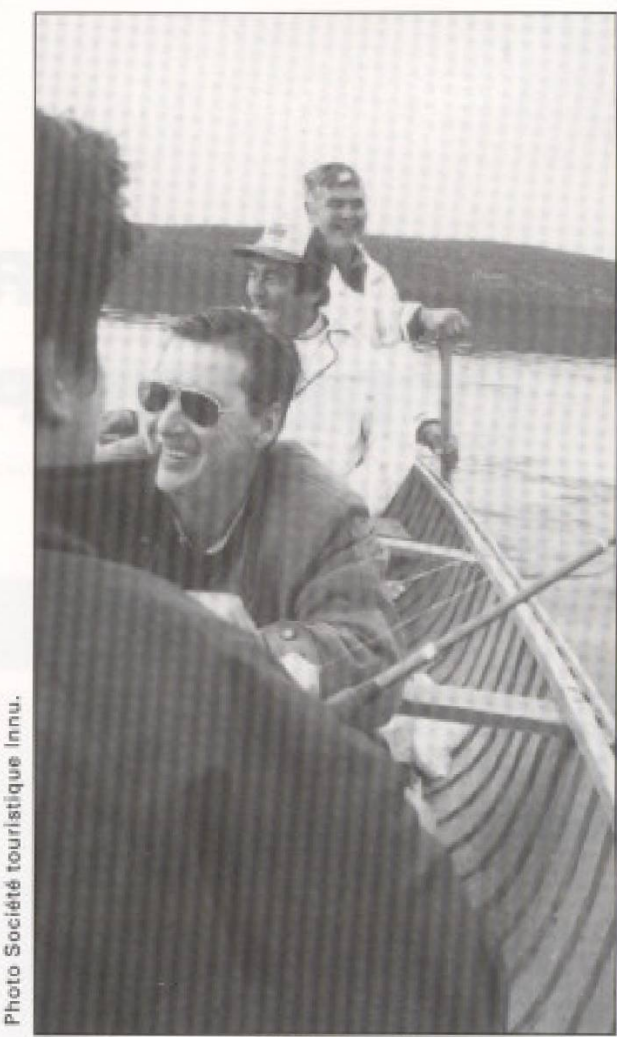

Une joyeuse expédition de pêche en canot.

\section{MARIE-MARTHE GABRIEL}

Le tourisme chez nous, à Schefferville, c'est une expérience de vie avec les Amérindiens. On leur fait vivre au mode de vie traditionnel et on leur fait voir les beautés de nos territoires. Il y a une grande diversité d'activités possibles dans l'aventure qu'on offre. Les gens sont toujours satisfaits lorsqu'il repartent et heureux d'avoir vécu une telle expérience. (Rendez-vous autochtone 1997)

\section{NICOLE O'BOMSAWIN}

De plus en plus le touriste recherche le contact avec l'authentique. Nécessairement cette authenticité doit être vécue à travers la culture, notre culture. Notre peuple se fait un plaisir d'enseigner le plus possible les valeurs, les coutumes et les racines dont il est fier. Le touriste se rapproche des valeurs de partage et de respect véhiculées par nos nations autochtones. (Rendez-vous autochtone 1997)

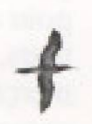

